\title{
Supplemental oxygen and exercise ability in chronic obstructive airways disease
}

\author{
A C DAVIDSON, R LEACH, R J D GEORGE, D M GEDDES
}

\author{
From the London Chest Hospital, London
}

\begin{abstract}
The influence of supplemental oxygen on exercise performance was assessed in 17 patients with severe airflow obstruction. Exercise capacity was measured by the six minute walking distance, by an endurance walking test, and by an endurance cycling test and comparison was made with performance when the patient was breathing air. In addition, the relation between the flow rate of supplemental oxygen and cycling endurance time was studied. Portable oxygen $\left(41 \mathrm{~min}^{-1}\right)$ carried by the patient increased the mean endurance walking time by $59 \%$ and the six minute walking distance by $17 \%$. The endurance time for cycling at a constant work load was increased by $51 \%$ with oxygen at a flow rate of $21 \mathrm{~min}^{-1}$, by $88 \%$ at $41 \mathrm{~min}^{-1}$, and by $80 \%$ at $61 \mathrm{~min}^{-1}$. Supplemental oxygen prolonged the length of time that the patients were able to walk at a fixed speed. It also increased the mean speed achieved during a six minute walk but this was variable and did not occur in all the subjects. The benefit from supplemental oxygen was not cancelled by the effort of carrying the portable cylinder.
\end{abstract}

\section{Introduction}

Supplemental oxygen may substantially increase exercise endurance in both obstructive ${ }^{12}$ and restrictive ${ }^{34}$ lung disease. Recent studies, in which exercise ability has been judged by the distance covered during timed walks, have found the improvement achieved in patients with obstructive lung disease to be small ${ }^{5}$ or even cancelled by the additional work of carrying the cylinder. ${ }^{6}$ Using a scoring system for breathlessness, Woodcock et al ${ }^{5}$ showed that portable oxygen conferred appreciable subjective benefit. These disparate results may have arisen from the types of exercise test used and the differing flow rates or concentrations of oxygen. Accordingly, the aims of the present study were $(a)$ to examine the relation between the results of tests of endurance and of an exercise test with a fixed time component; $(b)$ to determine the effect of different flow rates of supplemental oxygen on exercise performance; and $(c)$ to determine what clinical features, if any, might help in the selection of patients for treatment with portable oxygen.

Address for correspondence: Dr A C Davidson, Medical Unit, St Thomas's Hospital, London SE1 7EH.

(Reprints will not be available.)

Accepted 31 August 1988

\section{Methods}

\section{SUBJECTS}

Seventeen patients whose exercise tolerance was limited by breathlessness secondary to severe chronic airflow obstruction were studied when in a clinically stable condition. Angina, impaired cardiac function, or locomotor disability that might contribute to exercise limitation resulted in exclusion from the study. Informed consent was obtained. The results of pulmonary function tests at rest are summarised in table 1.

\section{OXYGEN DOSING STUDY}

The effect of different flow rates of oxygen on exercise endurance was assessed on a cycle ergometer at a constant workload. To determine an appropriate exercise level a progressive exercise test was performed. Workload was increased by 25 watt increments at minute intervals and maximum workload (Wmax) recorded. Endurance was assessed at a workload of $50-70 \% \mathrm{Wmax}$ as at this level exercise duration was restricted to about five minutes. Subjects sat with the nose clipped breathing through a low resistance valve (Hans Rudolf) connected on the expiratory side to a mixing chamber for mixed expired carbon dioxide and oxygen analysis (Capnograph and Servomex) and on the inspiratory side to a vane ventilometer 
(P K Morgan). A tube $20 \mathrm{~cm}$ long and $5 \mathrm{~cm}$ in diameter was attached to the inspiratory limb of the vane ventilometer and into the distal end a constant bias flow $\left(61 \mathrm{~min}^{-1}\right)$ was directed towards the ventilometer. By this means oxygen at different concentrations could be supplied to the subject without his knowledge. Accordingly, the bias flow composition was varied but was always at a flow rate of $61 \mathrm{~min}^{-1}$. Four conditions were tested-namely, zero (control), 2, 4, and $61 \mathrm{~min}^{-1}$ oxygen. Dry gas was supplied from compressed air or oxygen cylinders. No attempt was made to measure inspiratory gas composition. To ensure that the ventilometer performance was unaffected by such an arrangement, preliminary experiments were performed in which ventilation was measured in five subjects at rest and at two levels of exercise. The ventilometer measurements, with and without the bias flow, were compared with each other and with ventilation measured by inductance plethysmography (Respitrace). The difference between ventilation measurements with the ventilometer with and without the bias flow was under $10 \%$ and between ventilometer and Respitrace recordings under $15 \%$. The mean values were not significantly different.

Continuous measurements were made of minute ventilation (tidal volume $\times$ frequency, $\dot{V} E, B T P S$ ), heart rate, carbon dioxide production ( $\left.\mathrm{VCO}_{2}, \mathrm{BTPS}\right)$, and oxygen consumption ( $\mathrm{V}_{2}$, air breathing) and haemoglobin oxygen saturation $\left(\mathrm{HbSaO}_{2} \%\right.$, Biox III oximeter). No attempt was made to measure oxygen consumption during oxygen supplemented exercise. A computer (P K Morgan) provided breath by breath data, from which 30 second mean values were obtained. A subjective estimate of breathlessness was assessed by the visual analogue method, subjects being required to score breathlessness on a $10 \mathrm{~cm}$ line (marked at each end with "not at all breathless" and "extremely breathless") at one minute intervals, previous scores being hidden from the subject. The patients were encouraged to exercise for as long as was possible, the endurance time being noted at the end of cycling. Because of the importance of such

Table 1 Details of the 17 patients

\begin{tabular}{|c|c|c|}
\hline & Mean (SEM) & Range \\
\hline $\begin{array}{l}\text { Age (y) } \\
\text { FEV }(1) \\
\text { FVC(l) } \\
\text { RV/TLC (\%) } \\
\text { TLCo (\% pred) } \\
\text { KCO (\% pred) } \\
\mathrm{PaO}_{2}(\mathrm{kPa}) \\
\mathrm{PaCO}_{2}(\mathrm{kPa})\end{array}$ & $\begin{array}{cl}64.4 & (2 \cdot 1) \\
0.79(0.03) \\
2.14(0.11) \\
64.7(4.0) \\
53.2(5 \cdot 7) \\
69.4(5.9) \\
8.6(0.3) \\
6.0(0.4)\end{array}$ & $\begin{array}{l}39-74 \\
0 \cdot 45-1 \cdot 1 \\
1 \cdot 1-2 \cdot 9 \\
33-79 \\
33-79 \\
36-123 \\
6 \cdot 0-10 \cdot 7 \\
4 \cdot 2-8 \cdot 4\end{array}$ \\
\hline
\end{tabular}

FEV $_{1}$-forced expiratory volume in one second; FVC-forced vital capacity; RV-residual volume; TLC - total lung capacity; TLCocarbon monoxide transfer factor; $\mathbf{K c o}$-transfer coefficient; $\mathbf{P a O}_{2}$, $\mathrm{PaCO}_{2}$-arterial oxygen and carbon dioxide tensions. encouragement, ${ }^{7}$ the same investigator supervised all $\bar{C}$ testing and encouragement was provided in a standar- $\overline{\underline{\sigma}}$ dised fashion at intervals of one minute. Patients were $\frac{\bar{\omega}}{\vec{\partial}}$ familiarised with the visual analogue scoring before $\stackrel{\mathbb{Q}}{\Omega}$

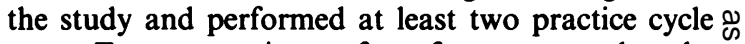
tests. For comparison of performance under the $\vec{\circ}$ different conditions the mean values for the exercise results were calculated for two, four, and six minutes $\vec{\omega}$ from the start of exercise.

\section{WALKING STUDIES}

Two tests of walking tolerance were performed. $\vec{N}$ Compressed air or oxygen was supplied from a $\mathscr{O}$ portable cylinder carried by the patient (Sabre AAV o $230,2.5 \mathrm{~kg}$ ) at a flow rate of $41 \mathrm{~min}^{-1}$. Nasal cannulas $ᄋ$ were used by most patients and a mask by five patients. A standard six minute walking test ${ }^{8}$ (6MW) was performed in an enclosed hospital corridor, at least three practice walks having previously been undertaken in view of the learning effect. ${ }^{7}$ The starting point $\underset{\mathbb{\Phi}}{\mathbb{D}}$ was varied and patients were encouraged to cover as much ground as possible, stops being allowed if $\mathscr{\infty}$ necessary. Visual analogue scores for breathlessness were recorded at one minute intervals and the distance covered was noted. For the endurance walk the subject was instructed to walk as far as possible (at a pace "as though late for an appointment") and to stop when unable to go any further. The endurance time and $\triangle$ distance covered were noted. Recovery time, assessed $\vec{\overrightarrow{ }}$ by asking the patients to indicate when they were no 3 longer feeling breathless, was recorded for both walking tests.

\section{PROTOCOL}

Patients were studied when clinically stable, this being $\stackrel{x}{x}$ confirmed by spirometry and body weight. Conditions were standardised for time of testing, omission of bronchodilators, and absence of smoking. The $O$ patients fasted for at least two hours before each study. The studies were usually performed over three $\frac{9}{2}$ consecutive days, no more than two cycling tests and $D$ two walking tests being carried out in one day. The practice sessions were held during the previous week. N $N$ A recovery period of at least three hours was allowed between tests. The order of testing in both the oxygen 0 dosing study and the walking tests was allocated $\omega$ randomly. For walking exercise the tests were perfor-? med double blind. For cycling endurance it wase necessary for the investigator to determine the bias $\mathbb{\Phi}$ flow composition and this part of the study was? therefore single (patient) blind. To ensure that this did $\frac{T}{T}$ not affect performance, care was taken to provide $\mathrm{a} \underset{\mathrm{D}}{\mathrm{O}}$ similar degree of encouragement as detailed above.

PULMONARY FUNCTION TESTING

Forced vital capacity (FVC) and forced expiratory 
1a Endurance Cycling Time

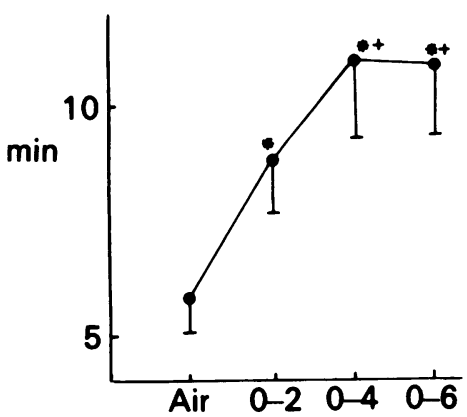

1c

Minute Ventilation

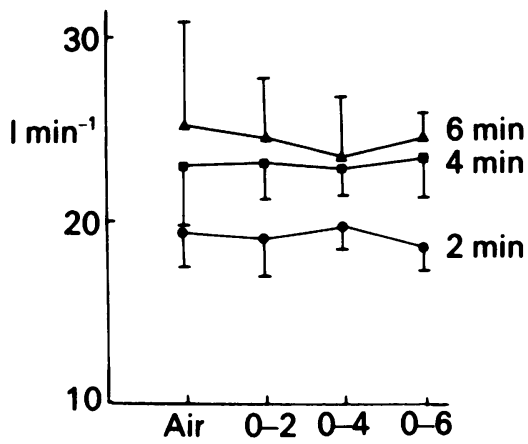

1b VAS

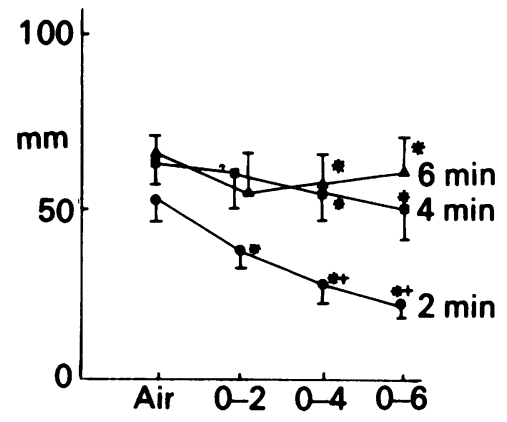

1d Hb-Saturation

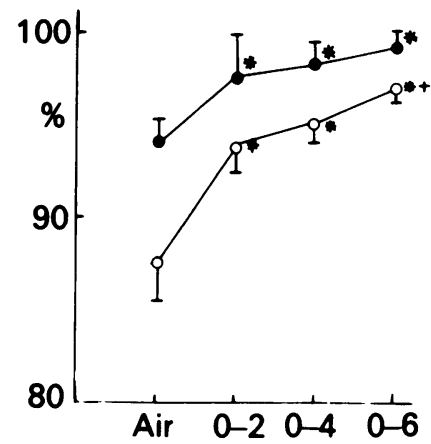

Fig 1 Group exercise data (means with SEM) for endurance cycling with the addition of 0 (control), 2,4 or $6 \mathrm{l} \mathrm{min}^{-1}$ oxygen (0-2, 0-4, 0-6). (a) Endurance exercise time; (b) visual analogue scale score for breathlessness (VAS);

(c) minute ventilation;

(d) haemogloblin saturation by ear oximetry at rest (filled circles) and lowest reading during exercise (open circles). $n=17$ except as indicated in table 2. ${ }^{*} p<0.02-0.01$ in the comparison with air; + $p<0.05-0.02$ in the comparison with oxygen at $21 \mathrm{~min}^{-1}$. volume in one second $\left(\mathrm{FEV}_{1}\right)$ was measured with a dry gas spirometer (Vitalograph) and total lung capacity (TLC) and residual volume (RV) by a constant volume body plethysmograph ( $\mathrm{P} K$ Morgan). The single breath method was used for measuring the carbon monoxide transfer factor (TLCO) and the transfer coefficient $(\mathrm{KCO})$ was calculated by adjustment for volume of ventilated lung (BTPS) by the helium dilution method (Morgan transfer test, model TTC). Arterial blood was drawn from either a radial or a brachial artery with the patient at rest (Radiometer ABL3).

\section{STATISTICAL ANALYSIS}

Wilcoxon's signed rank test was used for analysis of the exercise data, and linear and multilinear regression analysis was used for identifying factors relating to any change in performance with oxygen.

\section{Results}

\section{OXYGEN DOSING STUDIES}

Supplemental oxygen substantially increased cycling endurance. Exercise time was increased in all patients at the higher flow rates of oxygen $\left(4\right.$ and $\left.61 \mathrm{~min}^{-1}\right)$, but at $21 \mathrm{~min}^{-1}$ four patients showed no benefit. A clear dose-response relationship was apparent between oxygen flow rate and endurance time (fig la). Not all patients completed six minutes of exercise when breathing air or the low concentration of oxygen (table 2). Oxygen significantly reduced breathlessness scores (fig $1 b$ ) and the severity of arterial desaturation during exercise (fig $1 d$ ). The mean increase in endurance time was $51 \%$ (range $4-120 \% ; p<0.01$ ) at an oxygen flow rate of $21 \mathrm{~min}^{-1}, 88 \%$ (range 19-164\%; p < 0.01 ) at $41 \mathrm{~min}^{-1}$, and $80 \%$ (range $12-274 \% ; \mathrm{p}<0.01$ ) at $61 \mathrm{~min}^{-1}$.

The reduction in breathlessness was greater at the beginning of exercise. For example, at 2 minutes the visual analogue scale score was reduced by $29 \%, 46 \%$, and $54 \%$ as the oxygen flow rate was increased but at 6 minutes by only $14 \%, 13 \%$, and $6 \%$ (fig $1 b$, table 2 ). The fall in $\mathrm{HbSaO}_{2} \%$ during exercise $(6.9 \%$, range 1 $19 \%$ ) was less at the lower oxygen flow rates than with air breathing but was virtually abolished only at 6 $1 \mathrm{~min}^{-1}$ (fig $1 d$, table 2). Minute ventilation was unchanged by breathing an oxygen enriched gas mixture (fig $1 c$, table 2), values at rest and throughout exercise remaining constant despite the reduction in exercise desaturation. Inspection of individual results 
Table 2 Results (mean (SEM)) of the cycle endurance test, six minute walk, and endurance walk, in 17 patients (except where numbers in square brackets indicate otherwise), performed with portable compressed air ("oxygen flow rate 0") or oxygen

\begin{tabular}{|c|c|c|c|c|}
\hline & \multicolumn{4}{|c|}{ Supplemental oxygen flow rate $\left(1 \mathrm{~min}^{-1}\right)$} \\
\hline & 0 & 2 & 4 & 6 \\
\hline \multicolumn{5}{|l|}{ Endurance cycle test } \\
\hline Endurance time (min) & $5 \cdot 86(0 \cdot 8)$ & $8 \cdot 84(1 \cdot 3)^{*}$ & $11.0(1.8)^{*} \dagger$ & $10.9(1.6)^{*} \dagger$ \\
\hline $\begin{array}{l}\text { Visual analogue scale sco } \\
2 \mathrm{~min} \\
4 \mathrm{~min} \\
6 \mathrm{~min}\end{array}$ & $\begin{array}{l}52(6) \\
63(8)[12] \\
63(7)[10]\end{array}$ & $\begin{array}{l}37(5)^{*} \\
60(8)[15] \\
54(10)[13]\end{array}$ & $\begin{array}{l}28(6)^{*}+ \\
53(8)^{*}[16] \\
55(10)^{*}[14]\end{array}$ & $\begin{array}{l}24(5)^{*}+ \\
48(8)^{*+}+ \\
59(9)^{*}\end{array}$ \\
\hline $\begin{array}{l}\text { Ventilation }\left(1 \mathrm{~min}^{-1}\right) \\
2 \mathrm{~min} \\
4 \mathrm{~min} \\
6 \mathrm{~min}\end{array}$ & $\begin{array}{l}19 \cdot 6(2 \cdot 2) \\
23 \cdot 0(3 \cdot 7) \\
25 \cdot 3(5 \cdot 7)\end{array}$ & $\begin{array}{l}19 \cdot 0(2 \cdot 0) \\
23 \cdot 1(2 \cdot 1) \\
24 \cdot 6(3 \cdot 3)\end{array}$ & $\begin{array}{l}19 \cdot 8(1 \cdot 5) \\
23 \cdot 1(1 \cdot 8) \\
23 \cdot 3(3 \cdot 5)\end{array}$ & $\begin{array}{l}18.6(1.5) \\
23.5(1.4) \\
22.7(1.7)\end{array}$ \\
\hline $\begin{array}{l}\text { Carbon dioxide producti } \\
2 \mathrm{~min} \\
4 \mathrm{~min} \\
6 \mathrm{~min}\end{array}$ & $\begin{array}{l}532(70) \\
610(71) \\
663(96)\end{array}$ & $\begin{array}{l}529(78) \\
605(75) \\
684(92)\end{array}$ & $\begin{array}{l}551(58) \\
602(49) \\
648(63)\end{array}$ & $\begin{array}{l}519(51) \\
632(43) \\
676(51)\end{array}$ \\
\hline $\begin{array}{l}\text { Oxygen saturation (\%) } \\
\text { Rest } \\
\text { Exercise }\end{array}$ & $\begin{array}{l}94.0(1 \cdot 2) \\
87.5(2.0)\end{array}$ & $\begin{array}{l}97.5(1.5)^{*} \\
93.8(1.2)^{*}\end{array}$ & $\begin{array}{l}98.2(1.2)^{*} \\
95.0(0.9)^{*} \dagger\end{array}$ & $\begin{array}{l}99.2(0.9)^{*} \\
97.0(0.5)^{*}+\end{array}$ \\
\hline $\begin{array}{l}\text { Six minute walk } \\
\text { Distance (m) } \\
\text { Recovery time (min) }\end{array}$ & $\begin{array}{l}284(31) \\
2.4(0.3)\end{array}$ & & $\begin{array}{r}336(105)^{*} \\
2 \cdot 1(0 \cdot 3)\end{array}$ & \\
\hline $\begin{array}{l}\text { Endurance walk } \\
\text { Distance (m) } \\
\text { Time (min) } \\
\text { Recovery time (min) }\end{array}$ & $\begin{array}{l}282(55) \\
4 \cdot 5(0 \cdot 6) \\
2 \cdot 7(0 \cdot 3)\end{array}$ & & $\begin{array}{l}449(79)^{*} \\
7 \cdot 0(1 \cdot 0)^{*} \\
2 \cdot 1(0 \cdot 3)\end{array}$ & \\
\hline
\end{tabular}

* $p<0.05-0.01$ in the comparison with compressed air; $\nmid p<0.05-0.02$ in the comparison with oxygen at $21 \mathrm{~min}^{-1}$

confirmed the constancy of $\dot{V} E$ and showed no evidence of a change in ventilatory pattern.

\section{WALKING STUDIES}

For the six minute walk in which patients carried oxygen the mean distance walked was $51 \mathrm{~m}$ greater than with air $(17 \% ; p<0.01$ : fig 2 , table 2$)$. Five patients showed no benefit. The visual analogue scale score tended to be lower throughout exercise but was significantly reduced only for the six minute score $(\mathrm{p}<0.01)$.

Greater benefit was seen from oxygen in the endurance walk, with a mean increase in distance walked of $167 \mathrm{~m}(59 \%$; $<$ < 0.01: fig 2, table 2), all but one patient showing some benefit. Endurance time was increased by a similar proportion (55\%), so that patients walked further by walking for longer rather than walking faster. The distance walked in the two tests was closely related both for air and for oxygen (air: $r=0.77, p<0.001$; oxygen: $r=0.53, p<0.05$ ) but the range of performance in the endurance walk test was considerably greater, particularly when oxygen was used (fig 2). Recovery time was reduced by breathing oxygen but the difference was significant only for the endurance walk ( $p<0.05$ : table 2 ).
FACTORS INFLUENCING THE RESPONSE TO SUPPLEMENTAL OXYGEN

The change in performance with oxygen in all three exercise tests was unrelated to FVC, $\mathrm{FEV}_{1}, \mathrm{FEV}_{1} / \tilde{\Omega}$ FVC, the degree of hypoxaemia at rest, or oxygeno desaturation during exercise. In the cycling endurance. test increased endurance time correlated poorly withô reduction in breathlessness scores (oxygen $41 \mathrm{~min}^{-1}$ : $r=0.68, p<0.01$; NS for other oxygen flow rates).응 The change in the endurance walk test produced by supplemental oxygen correlated with the change in cycling endurance time $\left(61 \mathrm{~min}^{-1}: \mathrm{r}=0.71, \mathrm{p}<0.01\right.$, $\left.41 \mathrm{~min}^{-1}: \mathrm{NS} ; 21 \mathrm{~min}^{-1}: \mathrm{r}=0.52, \mathrm{p}<0.05\right)$; changes in performance in the two walking tests, however, were not correlated. There was an inverse relationshipt between $\mathrm{PaCO}_{2}$ and endurance cycling time $\left(61 \mathrm{~min}^{-1}, 0\right.$ $r=-0.60, \mathrm{p}<0.02 ; 41 \mathrm{~min}^{-1}: \mathrm{r}=-0.68, \mathrm{p}<0.05 \mathrm{O}$ $21 \mathrm{~min}^{-1}: \mathrm{NS}$ ) but not performance in the walking tests Both TLCO and KCO were correlated inversely with? change in the endurance walk with oxygen (TLCO:T $\mathrm{r}=-0.57, \mathrm{p}<0.025 ; \mathrm{KCO}: \mathrm{r}=-0.75, \mathrm{p}<0.002)$ (fig 3), but the relation was not significant for endurance cycling or for the six minute walk test.

Multivariate analysis was used to compare changein the walking or cycling tests with oxygen and the 


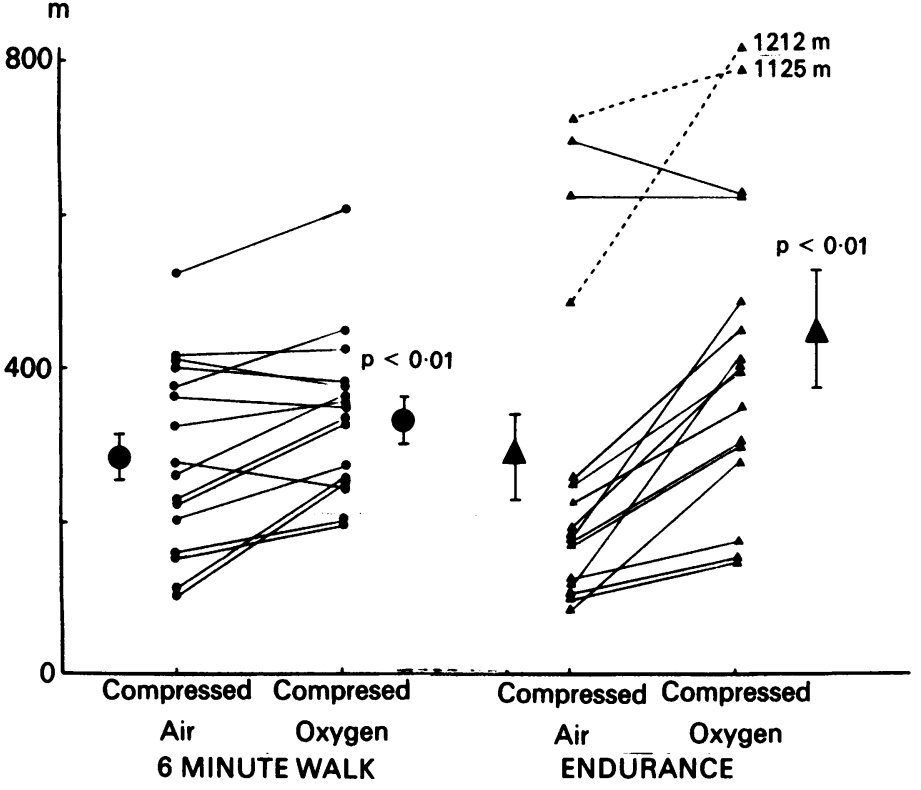

Fig 2 Individual and mean values (with $S E M)$ for distance walked ( $m$ ) in the six minute and the endurance walk. Compressed air or oxygen ( $4 \mathrm{l} \mathrm{min}^{-1}$ ) supplied by a portable cylinder carried by the patient. The dotted lines indicate values off scale.

variables $\mathrm{PaO}_{2}, \mathrm{PaCO}_{2}, \mathrm{FEV}_{1}, \mathrm{FVC}(\%$ predicted), $\mathrm{KCO}$ ( $\%$ predicted), and the fall in $\mathrm{HbSaO}_{2} \%$ during the cycling test. Only $\mathrm{KCO}$ and $\mathrm{PaCO}_{2}$ were found to contribute significantly, $\mathrm{KcO}$ accounting for $38 \%$ and $\mathrm{PaCO}_{2} 32 \%$ of the total variance.

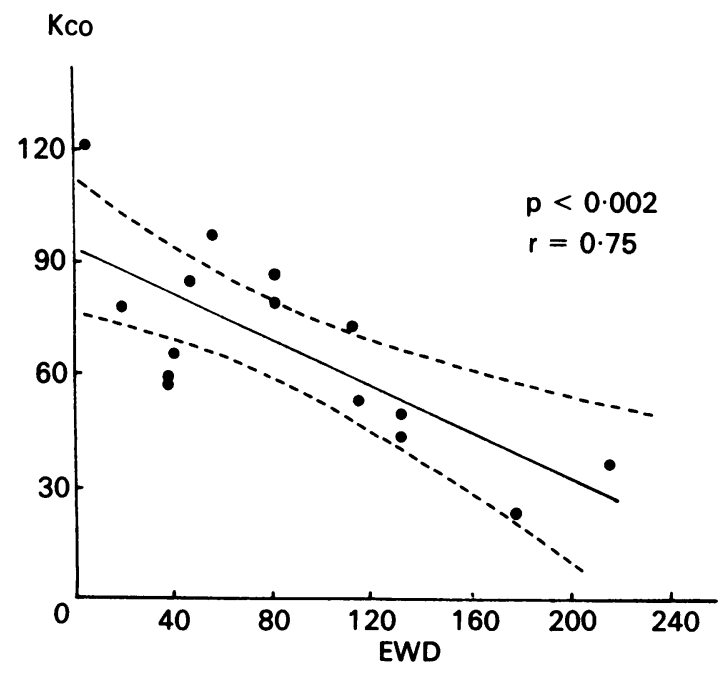

Fig 3 Relation of percentage increase in endurance walking distance to carbon monoxide transfer coefficient (KCO, \% predicted). The regression line is obtained by least squares analysis; the dotted line represents $95 \%$ confidence limits for the prediction $(n=15)$.

\section{Discussion}

Previous studies in patients with severe airflow obstruction have found the degree of benefit from supplemental oxygen during exercise to be highly variable. In studies of similar patients Bradley et al ${ }^{1}$ found performance to be increased by $52 \%$, Woodcock et al ${ }^{5}$ by $28 \%$, and Legget et al $^{6}$ by only $8 \%$. The present study suggests that these differences relate, in part, to the type of exercise studied. For endurance exercise (walking or cycling) performance was increased by $51-88 \%$ and in the test assessing distance walked in six minutes a $17 \%$ improvement occurred. This conclusion is supported by the findings of Woodcock et al, ${ }^{5}$ who reported increases of $28 \%$ in endurance treadmill performance with oxygen compared with $8 \%$ in the six minute walk test. In the present study the improvement in the endurance walk resulted because patients walked for longer before stopping rather than at a faster speed. Indeed, Bradley $e t$ al has shown that oxygen increases the endurance of submaximal exercise but does not increase the maximum workload that can be achieved.

In a previous study the extra effort of carrying the gas cylinder was found to cancel the benefit provided by supplemental oxygen. ${ }^{6}$ On the other hand, Woodcock et al reported that performance was equally improved by oxygen whether the cylinder was carried by the patient or by an assistant. In the present study the control walk was performed with air delivered from an identical portable cylinder and our findings therefore support the findings of Woodcock et al but 
also show the greater benefit gained in an endurance walk than in a timed walk. The sensitivity of the endurance walk is probably due to the fact that such a test assesses both ventilatory capacity and a component arising from the discomfort of such exercise, this "dyspnoea component" accounting for the greater range in walking distance in the endurance walk than in the six minute walk when patients are breathing air.

The importance of the flow rate or concentration of oxygen has previously received little attention. Cotes et $a l^{3}$ found evidence of a dose-response relation in patients with interstitial lung disease, endurance time increasing progressively as the oxygen content of the supplied gas was increased. This aspect may also account for the variable benefit previously reported. Analysis of the results of previous studies ${ }^{1-6}$ shows that the higher the oxygen flow rate the greater is the improvement in performance. Although the single blind nature of this part of the study is a potential source of error, the investigator was careful to avoid influencing the patients. Mean endurance cycling time was increased $51 \%$ when the bias flow contained 21 $\min ^{-1}$ supplementary oxygen and $88 \%$ when the oxygen flow rate was $41 \mathrm{~min}^{-1}$. Endurance was not on average increased further at an oxygen flow rate of $61 \mathrm{~min}^{-1}$, although individual patients did show further benefit. In practice, the limitation on high flow rates is the limited capacity of portable cylinders (200230 litres), although the use of oxygen conserving delivery systems ${ }^{9}$ might allow greater benefit while still providing a useful supply from a portable cylinder.

By using the visual analogue scoring method during exercise we were able to show a progressive reduction in breathlessness as oxygen flow rate was increased. Breathlessness scores were not uniformly lowered by oxygen and, as a result, the reduction in breathlessness correlated poorly with the increase in cycling endurance time. Minute ventilation was unaffected by supplemental oxygen despite the relief of oxygen desaturation during exercise. Although the vane ventilometer has previously been validated for exercise testing, ${ }^{10}$ given the type of exercise and the relatively low expected oxygen content of the inspiratory gas flow any depression of ventilation during exercise would be expected to be minor ${ }^{2311-16}$ and we may have failed to detect such a change. We found that neither resting $\mathrm{PaO}_{2}$ nor the relief of oxygen desaturation during exercise was related to the increase in exercise endurance, a finding previously reported by Stein $e t$ $a{ }^{2}$. This suggests that the mechanism by which endurance is increased is more complex than a reduction in minute ventilation. The possibilities include effects on the exercising muscles as a result of an increase in mixed venous $\mathrm{Po}_{2}$ and a reduction in that component of hypoxic dyspnoea that is independent of ventilation, ${ }^{14}{ }^{17}$ which may alter central perception and lead to greater resistance to the discomfort of $\frac{\bar{\sigma}}{\bar{D}}$ exercise. Until the factors that control exercise hyper- $\frac{\pi}{\vec{D}}$ pnoea $^{18}$ and their interaction with the subjective $\varnothing$ sensation of breathlessness ${ }^{19}$ are more clearly defined, ڤ the explanation of the beneficial effect of supplemental $\vec{\circ}$ oxygen on exercise remains speculative.

In the present study, as with previous studies in $\vec{\omega}$ obstructive lung disease, ${ }^{1256}$ factors such as vital capacity, degree of airflow obstruction, exercise $\vec{x}$ tolerance, and extent of desaturation were not found $\vec{\omega}$ to relate to the benefit resulting from oxygen. Oxygen $\vec{N}$ improved the endurance walk more consistently than 0 the six minute walk. The inverse correlation between of change in endurance walking distance and $\mathrm{Kco}$ (fig 3 ) 응 suggests that this measure of lung function might be useful in assessing which patients might benefit. Multivariate analysis showed that $\mathrm{KCO}$ and $\mathrm{PaCO}_{2}$, $\underset{\varnothing}{\mathbb{\infty}}$ both inversely related to the improvement in the $\frac{1}{3}$ endurance walking test with oxygen, accounted for $\mathbb{\mathbb { Q }}$ $70 \%$ of the variance; such a combination suggests that $\overrightarrow{\vec{\theta}}$ the "pink and puffing" type of patient is more likely to benefit. Although this combination might therefore be used as a guide to clinical selection, assessment should be offered to all patients with severe symptoms. In the present study four patients with preserved gas transfer $\bar{\partial}$ (Kco 74-85\% predicted) and carbon dioxide retention $\left(\mathrm{PaCA}_{2} 5 \cdot 4-7.9 \mathrm{kPa}\right)$ obtained considerable benefit with $\stackrel{\mathbb{Q}}{\circ}$ oxygen, endurance walking distance increasing by $46-\overrightarrow{\overrightarrow{0}}$ $110 \%$.

In conclusion, the findings of the present study help to explain the variability in benefit reported in? previous studies and confirm that considerable improvements in exercise tolerance may result from the use of portable oxygen in severe airflow obstruc- $x$ tion. As benefit cannot be clearly predicted by the $\frac{5}{3}$ results of lung function tests or blood gas analysis, $\mathrm{a}$ trial of oxygen is warranted in any severely dyspnoeic $ᄋ$ patient. Portable oxygen therapy enables patients with severe airflow obstruction to walk further rather than faster. For such a trial therefore the endurance walk is $\frac{?}{0}$ as sensitive as a more formal assessment on a cycle ergometer and more reliable than the more commonly $N_{0}$ used six minute walk.

\section{References}

1 Bradley BL, Garner AE, Billiu D, et al. Oxygen-assisted exercise in chronic obstructive lung disease. Am Rev? Respir Dis 1978;118:239-43.

2 Stein DA, Bradley BL, Miller WC. Mechanisms of oxygen effects on exercise in patients with chronic $\mathbb{D}$ obstructive pulmonary disease. Chest 1982;81:6-10.

3 Cotes JE, Gilson JC. Effect of oxygen on exercise ability in chronic respiratory insufficiency. Lancet 1956;ii: 872-6. 
4 Bye PTP, Anderson SD, Woolcock AJ, et al. Bicycle endurance performance of patients with interstitial lung disease breathing air and oxygen. Am Rev Respir Dis 1982;126:1005-12.

5 Woodcock AA, Gross ER, Geddes DM. Oxygen relieves breathlessness in "pink puffers". Lancet 1981;i:907-9.

6 Leggett RJE, Flenley DC. Portable oxygen and exercise tolerance in patients with chronic hypoxic cor pulmonale. $\mathrm{Br}$ Med J 1977;ii:84-6.

7 Guyatt GH, Pugsley SO, Sullivan MJ, et al. Effect of encouragement on walking test performance. Thorax 1984;39:818-22.

8 Butland RJA, Pang J, Gross ER, Woodcock A, Geddes DM. Two-, six-, and 12-minute walking tests in respiratory disease. $\mathrm{Br} \mathrm{Med} J$ 1982;284:1607-8.

9 Gould GA, Forsyth IS, Flenley DC. Comparison of two oxygen conserving nasal prong systems and the effects of nose and mouth breathing. Thorax 1986;41:808-9.

10 Cooper CB, Harris ND, Howard P. Evaluation of a turbine volume transducer in measurement of ventilation. Thorax 1987; 42:240P.

11 King AJ, Cooke NJ, Leitch AG, Flenley DC. The effects of $30 \%$ oxygen on the respiratory response to treadmill exercise in chronic respiratory failure. Clin Sci 1973; 44:151-62.

12 Cotes JE, Pisa Z, Thomas AJ. Effect of breathing oxygen upon cardiac output, heart rate, ventilation, systemic and pulmonary blood pressure in patients with chronic lung disease. Clin Sci 1963;25:305-21.

13 Cockcroft A, Beaumont A, Adams L, Guz A. Arterial oxygen desaturation during treadmill and bicycle exercise in patients with chronic obstructive airways disease. Clin Sci 1985;68:327-32.

14 Lane R, Cockcroft A, Adams L, Guz A. Arterial oxygen saturation and breathlessness in patients with chronic obstructive airways disease. Clin Sci 1987;72:693-8.

15 Swinburn CR, Wakefield JM, Jones PW. Relationship between ventilation and breathlessness during exercise in chronic obstructive airways disease is not altered by prevention of hypoxaemia. Clin Sci 1984;67:515-9.

16 Nery LE, Wasserman K, Andrews JD, et al. Ventilatory and gas exchange kinetics during exercise in chronic airways obstruction. J Appl Physiol Respirat Environ Exercise Physiol 1982;53:1594-602.

17 Adams L, Chronos N, Guz A. The dyspnogenic effect of hypoxia, dissociation from ventilatory response. Clin Sci 1981;63:17P.

18 Wasserman K, Whipp BJ, Casaburi M, et al. Ventilatory control during exercise in man. Bull Physiol Pathol Respir 1979;15:27-47.

19 Anonymous. The enigma of breathlessness. Lancet 1986; i:891-2. 